\title{
Variation in cassava germplasm for tolerance to post-harvest physiological deterioration
}

\author{
M.T. Venturini ${ }^{1}$, L.R. Santos ${ }^{1}$, C.I.A. Vildoso ${ }^{2}$, V.S. Santos ${ }^{2}$ and \\ E.J. Oliveira ${ }^{2}$ \\ ${ }^{1}$ Programa de Pós-Graduação em Ciência Agrárias, \\ Universidade Federal do Recôncavo da Bahia, Campus Universitário, \\ Cruz das Almas, BA, Brasil \\ ${ }^{2}$ Núcleo de Recursos Genéticos e Desenvolvimento de Variedades, \\ Embrapa Mandioca e Fruticultura, Cruz das Almas, BA, Brasil \\ Corresponding author: E.J. Oliveira \\ E-mail: eder.oliveira@embrapa.br
}

Genet. Mol. Res. 15 (2): gmr. 15027818

Received September 13, 2015

Accepted December 04, 2015

Published May 6, 2016

DOI http://dx.doi.org/10.4238/gmr.15027818

\begin{abstract}
Tolerant varieties can effectively control post-harvest physiological deterioration (PPD) of cassava, although knowledge on the genetic variability and inheritance of this trait is needed. The objective of this study was to estimate genetic parameters and identify sources of tolerance to PPD and their stability in cassava accessions. Roots from 418 cassava accessions, grown in four independent experiments, were evaluated for PPD tolerance $0,2,5$, and 10 days post-harvest. Data were transformed into area under the PPD-progress curve (AUP-PPD) to quantify tolerance. Genetic parameters, stability (Si), adaptability (Ai), and the joint analysis of stability and adaptability (Zi) were obtained via residual maximum likelihood (REML) and best linear unbiased prediction (BLUP) methods. Variance in the genotype $(\mathrm{G}) \mathrm{x}$ environment $(\mathrm{E})$ interaction and genotypic variance were important for PPD tolerance. Individual broad-sense heritability $\left(h_{g}^{2}=0.38 \pm 0.04\right)$ and average heritability in accessions $\left(h_{m g}^{2}=0.52\right)$ showed high genetic control of PPD tolerance. Genotypic correlation
\end{abstract}


of AUP-PPD in different experiments was of medium magnitude $\left(\hat{r}_{g A}=\right.$ 0.42 ), indicating significant $\mathrm{G} \times \mathrm{E}$ interaction. The predicted genotypic values of $\mathrm{G} \times \mathrm{E}$ free of interaction $\left(\hat{\mu}+\hat{g}_{i}\right)$ showed high variation. Of the 30 accessions with high $\mathrm{Zi}, 19$ were common to $\hat{\mu}+\hat{g}_{i}, \mathrm{Si}$, and Ai parameters. The genetic gain with selection of these 19 cassava accessions was $-55.94,-466.86,-397.72$, and $-444.03 \%$ for $\hat{\mu}+\hat{g}_{i}, \mathrm{Si}$, $\mathrm{Ai}$, and $\mathrm{Zi}$, respectively, compared with the overall mean for each parameter. These results demonstrate the variability and potential of cassava germplasm to introduce PPD tolerance in commercial varieties.

Key words: REML/BLUP; Manihot esculenta Crantz; Abiotic stress; Breeding; Post-harvest losses

\section{INTRODUCTION}

Cassava (Manihot esculenta Crantz) originated and diversified in South America, with Brazil considered to be the center of diversity (Allem, 2002). In general, cassava is highly adaptable to extreme climatic and soil conditions (high acidity and low-fertility soils and areas prone to drought and flooding) and also has high capacity for recovery after exposure to pests and disease (Morante et al., 2010). Currently, Brazil is the fourth-largest cassava producer, with production exceeding 21 million tons (FAO, 2014).

A major obstacle in the competitiveness of the cassava production chain compared to other starch crops is post-harvest physiological deterioration (PPD), which forces immediate marketing and processing of the root after harvest. While microbial deterioration occurs in subsequent steps, PPD is a physiological process, which quickly makes roots unpalatable and reduces their commercial value within 24-72 $\mathrm{h}$, depending on the cultivar and environmental conditions (Han et al., 2001; Reilly et al., 2003, 2007). In most cases, PPD develops from tissue damage, and dark blue staining of vascular tissue is observed, followed by a general discoloration of storage parenchyma (Buschmann et al., 2000; Koblitz, 2011). Microscopic analysis reveals the presence of colored occlusions and tyloses in xylem vessels, followed by an increase in respiration, changes in the lipid composition, accumulation of secondary metabolites, many with antimicrobial and antioxidant activity, and increased activity of several enzymes and peak levels of reactive oxygen species (Buschmann et al., 2000; Huang et al., 2001; Reilly et al., 2001, 2003, 2004; Iyer et al., 2010).

Several alternatives for PPD control have been proposed, such as excluding oxygen with the use of plastic bags during storage and transport of the roots, coating the roots with paraffin wax, controlled atmosphere storage with low oxygen content, and freezing roots (Paranaíba et al., 1996; Cereda and Vilpoux, 2003; Reilly et al., 2003; Luengo and Galbo, 2009). However, these strategies are impracticable for economic and technical reasons due to the high cost of their implementation in raw materials with low added value. In contrast, the development of cassava varieties that are more tolerant to PPD may represent a viable and low-cost method of generating roots that have high durability after harvest and hence better root utilization both for human consumption and industry (Fukuda, 2005; Morante et al., 2010). Since the 19', identifying sources of PPD tolerance has been one of the research priorities listed by the Food and Agriculture Organization of the United Nations (FAO) and the Cassava Biotechnology Network (Wenham, 1995). 
A first step in the development of cassava varieties tolerant to PPD is the identification of sources of tolerance in cassava germplasm. Recently, some authors have reported the existence of genetic variability for PPD tolerance (Morante et al., 2010; Salcedo et al., 2010). According to Morante et al. (2010), sources of PPD tolerance were identified in genotypes with high carotenoids levels, irradiated seeds in mutagenized populations, and waxy starch genotypes.

It has been suggested that PPD tolerance results from the effects of a few genes thought to be involved in plant defense mechanisms (Reilly et al., 2003, 2007). However, the genes involved in trait control are complex, considering the non-uniform variances resulting from the high environmental influence on the expression of PPD symptoms (Morante et al., 2010). The latter indicates the possibility of high genotypic instability of cassava accessions for PPD tolerance, depending on variables such as environmental cultivation, processing, and root analysis conditions.

For productivity traits, breeding programs traditionally promote the selection of the best genotypes using methods that consider the stability and adaptability for production. Therefore, the repetition of experiments under several environments (years and locations) is needed to better quantify the effects of genotype $(\mathrm{G}) \mathrm{x}$ environment (E) interactions and their possible impact on the selection and use of cultivars. This strategy can be used to select cassava genotypes with greater stability and adaptability to PPD tolerance to ensure the high reliability of genotype recommendations for crop production systems or as parents in crosses for introducing PPD tolerance to elite cultivars.

To identify genotypes that are better adapted and stable under certain planting conditions, accurate biometric and statistical tools should be used to estimate the environmental effects on PPD. In this respect, the restricted maximum likelihood/best linear unbiased prediction (REML/BLUP) method has the main advantage of randomness of genotypic effects when estimating the variance components by REML and predicting genotypic values for BLUP (Resende, 2002a). Considering genotypes as random effects ensures that the $\mathrm{G} \times \mathrm{E}$ interaction is not underestimated (Yang, 2007), while minimizing the mean square error in the prediction of the true-breeding values (Resende and Duarte, 2007).

The REML method has been widely used to estimate genetic parameters in breeding programs due to its desirable theoretical properties. A better understanding of the genetic parameters associated with PPD tolerance is important for the development of new cassava varieties, as they help to define the most effective breeding strategies for increasing gain with the selection. Despite this, information on genetic parameters for PPD tolerance, such as heritability, genetic correlation, gains with selection, and selective accuracy, has not been reported in the literature.

Analysis with mixed models also permits the selection of genotypes with high stability for certain traits, as well as the selection of responsive genotypes (with high adaptability) to specific environments. Furthermore, it enables the simultaneous selection by the three attributes (tolerance, stability, and adaptability) using the harmonic mean of the relative performance of genetic values (HMRPGV), which classifies the genotypic effects as random and therefore provides genotypic instead of phenotypic stability and adaptability (Resende, 2007). Therefore, the aim of this study was to evaluate part of the cassava germplasm from Brazil with regard to PPD tolerance, to estimate genetic parameters associated with this trait, to identify sources of PPD tolerance, and to evaluate the stability and adaptability of cassava accessions using mixed model methodology. 


\section{MATERIAL AND METHODS}

\section{Genetic material and experimental design}

A total of 418 cassava accessions from the Cassava Germplasm Bank (CGB) at Embrapa Cassava \& Fruits (Cruz das Almas, BA) were evaluated for PPD tolerance. The field tests were conducted in the same municipality in the agricultural years of 2011 and 2012 (first and second semester of each year). These four evaluation periods were considered independent environments for statistical analyses. In each environment, the experiments were composed of approximately 316-359 accessions.

Planting was performed using 20 -cm long cuttings, distributed in 10-cm deep grooves, with $0.9 \mathrm{~m}$ between rows and $0.8 \mathrm{~m}$ between plants, in plots of two rows of eight plants. The cultivation followed the recommendations of Souza et al. (2006). Roots were harvested manually 10 months after planting, and standard and commercial roots with no obvious mechanical damage were selected for PPD analysis.

\section{PPD evaluation}

On the day of assessment, the roots were washed under running water to remove excess soil, and were then stored on shelves in an open shed with free air circulation. The PPD assessments were performed $0,2,5$, and 10 days after harvest. Three cross-cuts were made along the roots from the proximal end. The thickness of the cut slices was about $1 \mathrm{~cm}$ at 25,50, and $75 \%$ of the total root length, referred to as proximal, medial, and distal, respectively. Next, the severity of PPD was evaluated according to two diagrammatic scales, one proposed by Wheatley and Schwabe (1985) for peripheral symptoms, and the second proposed by Venturini et al. (2015) for symptoms distributed throughout the root, both with variation in scores from 0 to $100 \%$. The PPD values for each root were calculated by averaging the scores of the three transverse slices. The experimental design was a randomized complete block design with three replicates and five roots per repetition.

Although the standard method for PPD analyses (Wheatley and Schwabe, 1985) discards the proximal and distal ends of the roots to accelerate the PPD, in this study the roots were evaluated without cutting, aiming to better simulate the cassava production system, especially by temporary storage in warehouses with or without roofing. The roots that showed rot symptoms related to deterioration by microorganisms, or were infested by insects, were not used in analyses of PPD tolerance.

The mean percentage PPD considering the evaluation of symptoms on the total and peripheral root area in the different dates was used to calculate the area under the PPD progress curve (AUP-PPD) according to the formula:

$$
A A C P D=\sum_{i=1}^{n} \frac{\left(Y_{i+1}+Y_{i}\right)}{2} x\left(T_{i+1}-T_{i}\right) \quad \text { Equation } 1
$$

where $n$ is the number of observations; $Y_{i}$ is the PPD severity in the $i$-th observation; $T_{i}$ is the time in days on the $i$-th observation. 


\section{Estimate of genetic gains and parameters}

For data analysis, an experimental design of incomplete blocks was used in four experiments, with one observation per plot using the statistical model

$$
y=X r+T b+Z g+W i+e \quad \text { Equation } 2
$$

where $y$ is the data vector, $r$ is the vector of the environment's effect (fixed) added to the overall mean, $b$ is the random-block effect within the environment, $g$ is the vector of randomgenotypic effects, $i$ is the vector of the random- $\mathrm{G} \times \mathrm{E}$ effects, and $e$ is the random-residual vector. $X, T, Z$, and $W$ are incidence matrices, which associate the unknown parameters $r, b, g$, and $i$, respectively, to the $y$ data vector.

The distribution and structure of means and variances are given by the following:

$$
y|\mathrm{r}, \mathrm{V} \sim N(\mathrm{Xr}, \mathrm{V}), b| \sigma_{b}^{2} \sim N\left(0, \mathrm{I} \sigma_{b}^{2}\right), g\left|\sigma_{g}^{2} \sim N\left(0, \mathrm{I} \sigma_{g}^{2}\right), i\right| \sigma_{i}^{2} \sim N\left(0,\left[\sigma_{i}^{2}\right), \text { and } e \mid \sigma_{e}^{2} \sim N\left(0, \mathrm{I} \sigma_{e}^{2}\right) \quad \text { Equation } 3\right.
$$

The covariance between all models of random effects is given by the following:

$$
\operatorname{Cov}\left(b, g^{\prime}\right) ; \operatorname{Cov}\left(b, i^{\prime}\right) ; \operatorname{Cov}\left(b, e^{\prime}\right) ; \operatorname{Cov}\left(g, i^{\prime}\right) ; \operatorname{Cov}\left(g, e^{\prime}\right) ; \operatorname{Cov}\left(i, e^{\prime}\right)=0 \quad \text { Equation } 4
$$

where

$$
E\left[\begin{array}{l}
y \\
b \\
g \\
i \\
e
\end{array}\right]=\left[\begin{array}{l}
X r \\
0 \\
0 \\
0 \\
0
\end{array}\right] \text { and } \operatorname{Var}\left[\begin{array}{l}
y \\
b \\
g \\
i \\
e
\end{array}\right]=\left[\begin{array}{lllll}
V & T P & Z G & W C & R \\
T^{\prime} & P & 0 & 0 & 0 \\
Z^{\prime} & 0 & G & 0 & 0 \\
W^{\prime} & 0 & 0 & C & 0 \\
R & 0 & 0 & 0 & R
\end{array}\right]
$$

Equation 5

where

$$
P=I \hat{\sigma}_{b}^{2} ; G=I \hat{\sigma}_{g}^{2} ; R=I \hat{\sigma}_{e}^{2} ; C=I \hat{\sigma}_{i}^{2} \text { and } V=T P T^{T}+Z G Z^{\prime}+W C W^{+}+R . \quad \text { Equation } 6
$$

The system of linear equations (mixed model equations; MME) that were used to obtain the solutions of the model was:

$$
\left[\begin{array}{l}
\hat{r} \\
\hat{b} \\
\hat{g} \\
\hat{i}
\end{array}\right]\left[\begin{array}{llll}
X^{\prime} X & X^{\prime} T & X^{\prime} Z & X^{\prime} W \\
T^{\prime} X & T^{\prime} T+I \lambda_{1} & T^{\prime} Z & T^{\prime} W \\
Z^{\prime} X & Z^{\prime} T & Z^{\prime} Z+G^{-1} \lambda_{1} & Z^{\prime} W \\
W^{\prime} X & W^{\prime} T & W^{\prime} Z & W^{\prime} W+I \lambda_{3}
\end{array}\right]^{-1}=\left[\begin{array}{c}
X^{\prime} y \\
T^{\prime} y \\
Z^{\prime} y \\
W^{\prime} y
\end{array}\right]
$$

Equation 7

where 
$\lambda_{1}=\frac{\sigma_{c}^{2}}{\sigma_{b}^{2}} \frac{1 \rho}{b^{2}}, \lambda_{2}=\frac{\sigma_{c}^{2}}{\sigma_{z}^{2}}=\frac{1 \rho \rho}{h_{z}^{2}}$ and $\lambda_{3}=\frac{\sigma_{c}^{2}}{\sigma_{i}^{2}}=\frac{1 \rho \rho}{i^{2}}$ are the shrinkage factors of the random effects of the mixed model equations, $c_{b}^{2}-\frac{\hat{b}_{b}^{2}}{\hat{b}_{t}^{2}+\hat{\theta}_{s}^{2} \hat{\sigma}_{t}^{2}+\hat{\sigma}_{c}^{2}}$ refers to the coefficient of determination of the block effect;

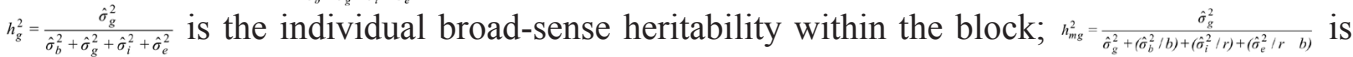
the mean genotypic heritability, wherein $r$ and $b$ are the number of environment and blocks, respectively; $\hat{r}_{g g}=\sqrt{h_{m_{g}}^{2}}$ is the accuracy of the selection of accessions; $c_{i}^{2}=\frac{\hat{\sigma}_{i}^{2}}{\hat{\sigma}_{b}^{2}+\hat{\sigma}_{g}^{2}+\hat{\sigma}_{i}^{2}+\hat{\sigma}_{e}^{2}}$ is the coefficient of determination of the individual effect within the block; $\hat{\sigma}_{b}^{2}$ is the variance of the block effect; $\hat{\sigma}_{g}^{2}$ is the genotypic variance among accessions; $\hat{\sigma}_{i}^{2}$ is the variance of the G x E effect; $\hat{\sigma}_{e}^{2}$ is the residual variance; $\hat{r}_{g A}=\frac{\hat{\sigma}_{g}^{2}}{\hat{\sigma}_{g}^{2}+\hat{\sigma}_{i}^{2}}$ is the genotypic correlation between the performance of accessions in different environments; $c v_{g}=\frac{\sqrt{\sigma_{g}^{2}}}{\bar{X}} \times 100$ is the coefficient of genotypic variation; $c_{c}=\frac{\sqrt{\sigma_{\bar{c}}^{2}}}{\bar{X}} \times 100$ is the residual coefficient of variation; and $\bar{X}$ is the overall mean.

REML estimates of the variance components were obtained using the expectation and maximization algorithm according to the following expressions: $\hat{\sigma}_{e}^{2}=\frac{y^{\prime} y-\hat{r}^{\prime} X^{\prime} y-b^{\prime} T^{\prime} y-\hat{g}^{\prime} Z^{\prime} y-i W^{\prime} y}{N-r(x)}$, $\hat{\sigma}_{b}^{2}=\frac{\hat{b}^{\prime} \hat{b}+\hat{\sigma}_{e}^{2} t r\left(C^{22}\right)}{q} \hat{\sigma}_{g}^{2}=\frac{\hat{g}^{\prime} G^{1} \hat{g}+\hat{\sigma}_{e}^{2} t r\left(C^{33}\right)}{s}$, and $\hat{\sigma}_{i}^{2}=\frac{\hat{i}^{\prime} \hat{i}+\hat{\sigma}_{e}^{2} t r C^{44}}{t}$, where $C^{22}, C^{33}$, and $C^{44}$ are derived from the coefficient matrix of the mixed model equations, i.e.;

$$
C^{-1}=\left[\begin{array}{llll}
C_{11} & C_{12} & C_{13} & C_{14} \\
C_{21} & C_{22} & C_{23} & C_{24} \\
C_{31} & C_{32} & C_{33} & C_{34} \\
C_{41} & C_{42} & C_{43} & C_{44}
\end{array}\right]^{-1}=\left[\begin{array}{llll}
C^{11} & C^{12} & C^{13} & C^{14} \\
C^{21} & C^{22} & C^{23} & C^{24} \\
C^{31} & C^{32} & C^{33} & C^{34} \\
C^{41} & C^{42} & C^{43} & C^{44}
\end{array}\right]
$$

Equation 8

which is the generalized inverse of the coefficient MME matrix, $t r$ is the trace of a matrix, $r(x)$ is the rank of the $\mathrm{X}$ matrix, $N-r(x)$ is the number of degrees of freedom of the error, $q$ is the number of blocks, $s$ is the number of accessions, and $t$ is the number of $\mathrm{G} \mathrm{x} \mathrm{E}$ combinations.

The empirical BLUP predictors of genotypic values free of the $\mathrm{G} \times \mathrm{E}$ interaction were given by $\hat{\mu}+\hat{g}_{i}$ where $\hat{\mu}$ is the AUP-PPD average of all environments and $\hat{g}_{i}$ is genotypic effect free of the $\mathrm{G} \times \mathrm{E}$ interaction. The prediction of the genotypic values, considering the average interaction $\left(g e_{m}\right)$ in different environments, was obtained by $\hat{\mu}_{j}+\hat{g}_{i}+\hat{g} e_{m}$, in which, $\hat{\mu}+\left[\left(\hat{\sigma}_{g}^{2}+\frac{\hat{\sigma}_{i}^{2}}{n}\right) \hat{\sigma}_{g}^{2}\right] \hat{g}_{i}$ and $\hat{\mu}$ is the overall mean for all environments, $n$ is the number of environments, and $\hat{g}_{i}$ is the genotypic effect of $i$ accession.

\section{Stability of genotypic values of PPD tolerance}

The stability of PPD tolerance in cassava accessions under different experiments (years and growing seasons) was evaluated by the harmonic mean of genotypic value ( $\mathrm{Si}$ ), given by $\sum_{i=\frac{n_{i}}{S_{i}}}^{\sum_{G_{j}}}$, where $n_{i}$ is the number of experiments where accession $i$ was evaluated, and $V G_{i j}$ is the genotypic value predicted by the $i$ accession in $j$ environment. The smaller the standard deviation of the accession in different environments, the greater the harmonic mean of their genotypic values. Therefore, the selection of the greatest Si values results in the simultaneous selection of accessions with high tolerance and stability to PPD. 
Using the concepts of stability and adaptability, which are widely employed in the analysis of productive attributes, the adaptability of accessions was calculated considering the relative performance of genotypic values in different experiments (Ai). The predicted genotypic values were expressed by the ratio of the overall mean of each environment, and then by obtaining the mean value of this ratio in the various environments. The Ai was obtained by ${ }_{A}=\frac{1}{n_{i}} \sum_{j=1}^{n_{i}} \frac{V G_{i j}}{\mu_{j}}$, where $n_{i}$ is the number of environments in which the accessions $i$ were evaluated; $\mu_{j}$ is the average of the $j$ environment; $V G_{i j}=\mu_{j}+g_{i}+g e_{i j}$ is the predicted genotypic value of the $i$ accession in the $j$ environment, where $g_{i}$ is the genotypic effect of the $i$ accession; and $g e_{i j}$ is the interaction effect of $i$ accession in the $j$ environment, estimated by REML/BLUP.

The stability and adaptability for PPD tolerance was estimated by the method of harmonic mean of the relative performance of genotypic value (Zi), predicted by $\sum_{j=1}^{Z_{i}=\frac{n_{i}}{n_{i}} \frac{1}{P R G_{i j}}}$, according to the methods described by Resende (2007). The estimation of variance components and effects of non-biased prediction were performed by REML.

The genetic gains were calculated using the average genotypic values of the selected accessions compared to the average of all experiments. The selection was carried out using the genotypic values of the best 30 accessions (lower estimates of BLUP values for PPD tolerance). The genotypic values of each accession were obtained by adding the general mean to the genotypic effect.

The BLUP procedure was adopted to predict the genotypic values using estimates of variance components obtained by REML. All analyses were performed by the Selegen software (Resende, 2002b), using an incomplete block design to simultaneously estimate the genotypic values and the variance components.

\section{RESULTS AND DISCUSSION}

\section{Estimates of genetic parameters}

The effects of genotypes free of a $\mathrm{Gx} E$ interaction and the effect of the environment and $\mathrm{G} \times \mathrm{E}$ interaction were significant by $\chi^{2}(\mathrm{P}<0.1 \%)$ according to deviance analysis (Table 1$)$. These results demonstrate the importance of each component in the expression of cassava tolerance to PPD, especially when considering the $\mathrm{G} x \mathrm{E}$ interaction, which in this case, requires specific analysis for the appropriate recommendation of genotypes, as for the analyzes of stability and adaptability.

Table 1. Deviance estimates for tolerance to post-harvest physiological deterioration (PPD) in cassava.

\begin{tabular}{l|c|c|c}
\hline Effect & Deviance $^{1}$ & LRT $\left(\chi^{2}\right)$ & Significance \\
\hline Genotype (G) & $23,119.80$ & 41.80 & 0.000 \\
\hline Environment (E) & $23,091.03$ & 13.03 & 0.000 \\
\hline Gx E & $24,001.04$ & 923.04 & 0.000 \\
\hline Complete model & $23,078.00$ & & \\
\hline
\end{tabular}

${ }^{1}$ Deviance: adjusted model without the corresponding effect; distribution for 1 degree of freedom. LRT: likelihood ratio test, with $\chi^{2}$ distribution.

The significance of the genotypic effects indicates that the genetic variability is sufficient for selecting cassava accessions that are tolerant to PPD. This can be confirmed by 
the wide variation in AUP-PPD values observed (633.04-2265.19) (Table 2), which permit the selection of the best accessions based on more appropriate statistical-genetic methods considering the genotypic effects of the trait under selection.

Table 2. Estimates of variance components and genetic parameters of the joint analysis of experiments related to the evaluation of PPD in cassava.

\begin{tabular}{l|c}
\hline Parameter & Estimate \\
\hline$\sigma_{g}^{2}$ & $183,687.79$ \\
\hline$\sigma_{b}^{2}$ & 893.41 \\
\hline$\hat{\sigma}_{i}^{2}$ & $253,061.97$ \\
\hline$\sigma_{e}^{2}$ & $52,706.44$ \\
\hline$\sigma_{f}^{2}$ & $490,349.61$ \\
\hline$h_{g}^{2}$ & $0.38 \pm 0.04$ \\
\hline$h_{m g}^{2}$ & 0.52 \\
\hline$\hat{r}_{g g}$ & 0.72 \\
\hline$c_{G x A}^{2}$ & 0.52 \\
\hline$\hat{r}_{g A}$ & 0.42 \\
\hline$C V_{g}$ & 26.68 \\
\hline$C V_{e}$ & 14.29 \\
\hline $\bar{X}$ & 1606.24 \\
\hline Range & $633.04-2265.19$ \\
\hline
\end{tabular}

$\hat{\sigma}_{g}^{2}$ : genotypic variance; $\hat{\sigma}_{b}^{2}$ : variance between blocks; $\hat{\sigma}_{i}^{2}$ : variance of the environment x genotype (G x E) interaction; $\hat{\sigma}_{e}^{2}$ : residual variance; $\sigma_{f}^{2}$ : phenotypic variance; $h_{g}^{2}$ : individual broad-sense heritability within the block; $h_{m g}^{2}$ : average heritability of accessions through all environments; $\hat{r}_{g g}$ : accuracy of genotype selection; $c_{G x A}^{2}$ : coefficient of determination of the GxE interaction; $\hat{r}_{g A}$ : genotypic correlation of the genotype behavior in different environments; $c v_{g}$ : genotypic coefficient of variation; $c v_{e}$ : residual coefficient of variation; $\bar{X}$ : overall mean.

Variances in the $\mathrm{G} \times \mathrm{E}$ interaction $\left(\hat{\sigma}_{i}^{2}\right)$, genotypic variance $\left(\sigma_{g}^{2}\right)$, and environmental variance $\left(\sigma_{e}^{2}\right)$ were most important for the expression of PPD tolerance, representing 52, 37, and $11 \%$ of the phenotypic variance, respectively (Table 2). In studies related to potential rice production, similar proportions were observed between the genotypic variance and the G x E interaction (Colombari Filho et al., 2013), indicating that the effects of the G $\mathrm{x}$ E interaction strongly influence the expression of quantitative traits. In contrast, when evaluating the fresh root yield in 10 cassava varieties, Farias Neto et al. (2013) reported that most of the variation was due to the environmental effect (79\%) over the G x E interaction (18\%) and genotypic variation (3\%). Furthermore, Oliveira et al. (2015) evaluated the effect of drought on genetic parameters and genotypic values for dozens of cassava accessions. According to those authors, the $\sigma_{g}^{2}$ estimates were generally more important than the $\sigma_{e}^{2}$ estimates, although in environments with drought $\sigma_{g}^{2}$ estimates were 3-, 9-, 10-, and 12-fold lower than those obtained in environments with full irrigation. This indicates that although genetic components are significant in the genetic control of quantitative traits, the environment may greatly influence the expression of those traits responsible for most of the phenotypic variation.

The individual broad-sense heritability was of medium magnitude $\left(h_{g}^{2}=0.38 \pm 0.04\right)$. Medium estimates of $h_{g}^{2}(0.30)$ were also observed in the cassava crop-to-shoot yield in water stress conditions (Oliveira et al., 2015). In contrast, high magnitudes of $h_{g}^{2}(0.74)$ were observed 
for cyanogenic compounds (Oliveira et al., 2014) and root and starch yield (0.80) (Oliveira et al., 2015). Heritability is one of the most important genetic parameters, because it quantifies the fraction of heritable phenotypic variation, which can be exploited during selection (Rosado et al., 2012). Therefore, a medium magnitude of $h_{g}^{2}$ indicates that selection based on individual plants and in a few environments of evaluation would not be an effective strategy to increase PPD tolerance in cassava, because agronomic evaluations should be carried out in various environments and years of cultivation.

The mean genotypic heritability to the four environments $\left(h_{m g}^{2}\right)$ to AUP-PPD was higher $(0.52)$ than $h_{g}^{2}$, indicating good genetic control of PPD tolerance expression. $h_{m g}^{2}$ is a parameter of interest for predicting breeding success when selecting clones, because the genotypic values are predicted based on the average obtained from several repetitions (Maia et al., 2009). Indeed, Oliveira et al. (2015) observed a significant improvement in estimates of $h_{m g}^{2}$ compared to those of $h_{g}^{2}$, both in the absence and presence of water stress in cassava experiments. For example, the characteristic number of roots presented $h_{g}^{2}=0.25 \pm 0.12$ and $h_{m g}^{2}=0.50$, having twice the heritability of the trait, when considering the adjusted average of genotypes.

According to Resende (2002a), selective accuracy $\left(\hat{r}_{g g}\right)$ can be classified as high $\left(\hat{r}_{g g}\right.$ $>0.70)$, medium $\left(0.40<\hat{r}_{g g}<0.70\right)$, and low $\left(0.10<\hat{r}_{g g}<0.40\right)$. The AUP-PPD presented a high magnitude (0.72), which would ensure high reliability when selecting the best accessions. In another study related to fresh root yield in cassava, Farias Neto et al. (2013) reported success in selecting superior genotypes even when a selective accuracy of moderate magnitude (0.53) was observed. However, those authors noted that an appropriate number of repetitions is essential in field trials for a more efficient and accurate selection, because it can contribute to an increase in the $\hat{r}_{g g}$. Additionally, Resende and Duarte (2007) suggested that in the intermediate stages of breeding programs, the $\hat{r}_{g g}$ should be at least 0.70 . Therefore, the data on AUP-PPD have good selective accuracy for indicating cassava accessions that have high potential for use in breeding programs.

The coefficient of determination of the G x E interaction $\left(c_{G \times A}^{2}\right)$ for the different experiments was 0.52 (Table 2). The high $c_{G x A}^{2}$ resulted in a medium estimate of genotypic correlation between AUP-PPD values of cassava accessions in different experiments $\left(\hat{r}_{g A}=0.42\right)$. Similar results were observed in sugarcane by Bastos et al. (2007) and rice by Colombari Filho et al. (2013), in which $\hat{r}_{g A}$ values were 0.49 and 0.47 , respectively. On the other hand, Farias Neto et al. (2013) reported low genotypic correlation for fresh root yield in different environments for cassava (0.15). The $\hat{r}_{g A}$ parameter depends on the environmental growing conditions, the nature of the genetic material, and the trait evaluated, considering that in other crops such as sugarcane and coffee, the genotypic correlation of genotypes in different environments is quite high, e.g., 0.80 for stem yield (Oliveira et al., 2005) and 0.93 for grain yield (Rodrigues et al., 2013). However, unlike the present study, in which 418 cassava genotypes were evaluated, the aforementioned studies evaluated only a few dozen genotypes. Indeed, differences in the nature of the trait and the number of genotypes used may make it more difficult to order genotypes in different environments, considering the great effect of $\mathrm{G} x \mathrm{E}$ interaction.

According to Resende (2007), $\hat{r}_{g A}$ can be used as an indicator of the type of interaction in which $\hat{r}_{g A} \geq 0.70$ indicates a simple, and $\hat{r}_{g A}<0.70$ indicates a complex interaction. Therefore, according to that author, the existing interaction of PPD tolerance in cassava is complex, and the classification of accessions in different experiments is altered. Thus, selection of the best genotypes should not be made solely on the basis of the average experiment. 
The genotypic coefficient of variation $\left(c v_{g}\right)$ was high (26.68\%), indicating the existence of genetic variability to select for PPD tolerance. This value was twice that estimated in the analysis of sugarcane clones for productivity, which were evaluated in five of seven sites (Bastos et al., 2007). Values above $10 \%$ indicate the presence of genetic variability with the potential for selection (Oliveira et al., 2005; Bastos et al., 2007). The residual coefficient of variation $\left(c v_{e}\right)$ was $14.29 \%$, which is considered of medium magnitude, because according to Gomes (2000), $c v_{e}$ less than $10 \%$ can be classified as low magnitude, and values above $30 \%$ are considered very high magnitude, and compromise the experimental accuracy. Similar results obtained in the present study, with $c v_{e}=20.93 \%$, were observed for other character in cassava, such as fresh root yield (Farias Neto et al., 2013). In contrast, $c v_{e}$ above $50 \%$ was observed for root and stem productive traits in cassava (Aina et al., 2007; Oliveira et al., 2015).

As the classification described by Gomes (2000) is very comprehensive and does not consider the number of repetitions nor the greatness of the trait under selection, Resende (2007) suggested using the relative coefficient of variation $\left(C V_{r}=c v_{g} / c v_{e}\right)$ to assess the experimental quality of the trials. For PPD, the $C V_{r}$ was above one (1.87), and therefore increased the possibility of gains when selecting for this trait. A $C V_{r}$ value above the unit has been reported for other productive traits in cassava, such as the number and root yield, shoot yield, dry matter content, and starch yield (Oliveira et al., 2015).

\section{Genotypic values of the PPD tolerance}

The average performance of the 30 best cassava accessions based on the predicted genotypic values free of $\mathrm{G} \times \mathrm{E}$ interaction $\left(\hat{\mu}+\hat{g}_{i}\right)$, and the genotypic values capitalizing the $\mathrm{G}$ $\mathrm{x}$ E interaction $\left(\hat{\mu}_{j}+\hat{g}_{i}+\hat{g}_{m}\right)$, are presented in Table 3 . The classification of accessions tolerant to PPD followed the same order for the two criteria $\left(\hat{\mu}+\hat{g}_{i}\right.$ and $\left.\hat{\mu}_{j}+\hat{g}_{i}+\hat{g}_{m}\right)$, although estimates of the mean genotypic values were of low magnitude because the latter criterion considers the capitalization of the average interaction to reduce the mean value of the trait (less PPD severity). Similar observations were reported in sugarcane, in which the parameter $\hat{\mu}_{j}+\hat{g}_{i}+\hat{g}_{m}$ permitted the capitalization of a larger proportion of sugar yield trait (Gonçalves et al., 2014). However, those authors warned that this superiority is only capitalized when the varieties are planted in areas with the same G x E interaction patterns. On the other hand, the $\hat{\mu}+\hat{g}_{i}$ parameter allows extrapolation of the results to locations outside the experimental evaluation network, since the performance of the materials is free from $\mathrm{G} x \mathrm{E}$ interaction. In situations outside of these specifications, the selection of better accessions based on $\hat{\mu}+\hat{g}_{i}$ values is safer. Therefore, as there was no change in the ranking of cassava accessions for PPD tolerance, we adopted the ranking based on lower $\hat{\mu}+\hat{g}_{i}$ estimates.

The selection and asexual multiplication of the best cassava accessions explores the predicted total genotypic values of each accession (additive, dominant, and epistatic), because the individual genotype will be fully transmitted to the next generation, contrary to what is practiced in recurrent selection in which the knowledge of additive effects becomes more important than that of non-additive effects. Therefore, genetic gains with selection can be based on the total genotypic values for PPD tolerance.

The number of accessions to select is dependent on the future vision of the breeding programs, with their results related to genetic gains, and the maintenance of genetic variability depending on the intensity of selection practiced at each breeding stage. In a long-term program aiming to introduce PPD tolerance, the selection of the 30 best accessions (more tolerant) 
resulted in a reduction of $55.75 \%$ in the $\hat{\mu}+\hat{g}_{i}$ estimates, compared with the average of the 418 evaluated accessions. In contrast, short-term breeding programs can adopt a higher intensity of selection, in which selection of only the five most tolerant accessions to PPD (BGM1209, BGM0624, BGM1190, BGM0930, and BGM1370) provides a reduction in PPD severity of over 103\% (Table 3). This reduction in PPD severity was significant, considering that genetic gains of only $2.28 \%$ were reported for cassava fresh root yield when the $\hat{\mu}+\hat{g}_{i}$ parameter was used to select the three best genotypes (Farias Neto et al., 2013).

Table 3. Estimates of the predicted genotypic values $\left(\hat{\mu}+\hat{g}_{i}\right)$, genotypic values capitalizing the $\mathrm{G} \times \mathrm{E}$ interaction $\left(\hat{\mu}_{j}+\hat{g}_{i}+\hat{g}_{m}\right)$, and genetic gains for tolerance to physiological deterioration in cassava accessions.

\begin{tabular}{|c|c|c|c|c|c|}
\hline Rank & Accession & $\hat{\mu}+\hat{g}_{i}$ & Gain (\%) & New average & $\hat{\mu}_{j}+\hat{g}_{i}+\hat{g} e_{m}$ \\
\hline 418 & BGM1209 & 633.04 & -153.73 & 633.04 & 297.85 \\
\hline 417 & BGM0624 & 658.78 & -148.68 & 645.91 & 332.46 \\
\hline 416 & BGM1190 & 806.47 & -129.65 & 699.43 & 531.01 \\
\hline 415 & BGM0930 & 909.33 & -113.62 & 751.91 & 669.30 \\
\hline 414 & BGM1370 & 946.38 & -103.12 & 790.80 & 719.11 \\
\hline 413 & BGM0928 & 977.42 & -95.43 & 821.90 & 760.84 \\
\hline 412 & BGM1179 & 985.59 & -90.02 & 845.29 & 771.82 \\
\hline 411 & BGM0626 & 989.88 & -86.05 & 863.36 & 777.59 \\
\hline 410 & BGM0356 & 1013.29 & -82.52 & 880.02 & 809.06 \\
\hline 409 & BGM1342 & 1025.98 & -79.55 & 894.62 & 826.13 \\
\hline 408 & BGM0367 & 1045.26 & -76.84 & 908.31 & 852.05 \\
\hline 407 & BGM0878 & 1050.36 & -74.56 & 920.15 & 858.91 \\
\hline 406 & BGM1371 & 1057.15 & -72.59 & 930.69 & 868.03 \\
\hline 405 & BGM0623 & 1058.56 & -70.91 & 939.82 & 869.93 \\
\hline 404 & BGM0497 & 1064.82 & -69.41 & 948.15 & 878.35 \\
\hline 403 & BGM1137 & 1079.22 & -67.96 & 956.35 & 897.70 \\
\hline 402 & BGM0640 & 1084.46 & -66.64 & 963.88 & 904.74 \\
\hline 401 & BGM1567 & 1089.50 & -65.45 & 970.86 & 911.53 \\
\hline 400 & BGM1024 & 1090.90 & -64.38 & 977.18 & 913.40 \\
\hline 399 & BGM1185 & 1094.98 & -63.39 & 983.07 & 918.89 \\
\hline 398 & BGM0631 & 1101.55 & -62.46 & 988.71 & 927.72 \\
\hline 397 & BGM0452 & 1110.25 & -61.56 & 994.23 & 939.42 \\
\hline 396 & BGM1508 & 1110.76 & -60.74 & 999.30 & 940.11 \\
\hline 395 & BGM1184 & 1114.50 & -59.97 & 1004.10 & 945.14 \\
\hline 394 & BGM1291 & 1126.09 & -59.19 & 1008.98 & 960.71 \\
\hline 393 & BGM0276 & 1127.32 & -58.48 & 1013.53 & 962.38 \\
\hline 392 & BGM1236 & 1143.83 & -57.73 & 1018.36 & 984.56 \\
\hline 391 & BGM0601 & 1144.62 & -57.03 & 1022.87 & 985.63 \\
\hline 390 & BGM0307 & 1146.18 & -56.38 & 1027.12 & 987.73 \\
\hline 389 & BGM1037 & 1151.45 & -55.75 & 1031.26 & 994.81 \\
\hline 2 & $9624-09$ & 2211.00 & -0.10 & 1604.66 & 2419.29 \\
\hline 165 & $\overline{98150-02}$ & 1711.72 & -13.86 & 1410.76 & 1748.05 \\
\hline 220 & BRS Aipim Brasil & 1605.30 & -19.65 & 1342.46 & 1604.97 \\
\hline 26 & BRS Caipira & 2053.31 & -2.08 & 1573.47 & 2207.29 \\
\hline 277 & BRS Dourada & 1473.33 & -27.34 & 1261.42 & 1427.55 \\
\hline 206 & $\overline{\text { BRS Gema de Ovo }}$ & 1631.74 & -18.05 & 1360.66 & 1640.52 \\
\hline 242 & BRS Tapioqueira & 1561.11 & -22.38 & 1312.52 & 1545.57 \\
\hline 11 & BRS Verdinha & 2111.00 & -0.87 & 1592.41 & 2284.85 \\
\hline 330 & Eucalipto & 1322.99 & -36.79 & 1174.25 & 1225.44 \\
\hline
\end{tabular}

Accessions underlined and italicized refer to the local or improved varieties, used as control. Accessions underlined and italicized refer to the local or improved varieties, used as witnesses.

Considering the varieties used by farmers, the three more tolerant to PPD were represented by the local variety, Eucalipto, and the improved varieties BRS Dourada and BRS Tapioqueira, which were allocated in 330th, 277th, and 242nd rank position, respectively. 
Indeed, the variety Eucalipto has been widely grown in the Recôncavo region of Bahia (Brazil) for its culinary characteristics and for its greater PPD tolerance. However, the value of AUP-PPD (1322.99) is very close to the overall mean, indicating the existence of more tolerant materials.

The predicted values of the most PPD-tolerant accession may also be considered for recommendations, even when selected in environments with a different pattern of $\mathrm{G} x$ E interaction. Due to the conservative nature of the $\hat{\mu}+\hat{g}_{i}$ estimates, which penalizes the predicted genotypic values, it is expected that the same genotypic means of the trait would be observed under different environments (Maia et al., 2009). In this context, the use of improved prediction methods, such as BLUP, provides greater accuracy in the selection, evaluation, and selection of superior genotypes.

\section{Estimates of stability and adaptability for PPD tolerance}

Table 4 shows the harmonic mean of the predicted genotypic values, which defines stability $(\mathrm{Si})$, and the relative performance of genotypic values, which defines the adaptability of accessions (Ai) for PPD tolerance. Of the 30 most stable cassava accessions for PPD tolerance, $60 \%$ were also ranked with lower $\hat{\mu}+\hat{g}_{i}$ (BGM0452, BGM0601, BGM0623, BGM0624, BGM0626, BGM0640, BGM0878, BGM1024, BGM1037, BGM1190, BGM1209, BGM1236, BGM1291, BGM1342, BGM1370, BGM1371, BGM1508, and BGM1567). Therefore, there was a good correlation between the genotypic values free of $\mathrm{G} \times \mathrm{E}$ interaction and the Si parameter, which shows that the accessions more tolerant to PPD also presented high stability. Indeed, according to Oliveira et al. (2005), the lower the standard deviation of genotypic performance between environments, the higher the Si, which means that selecting for the Si parameter results in the simultaneous selection for the trait of interest, which is associated with their stability in different experiments. On the other hand, inconsistencies in the ranking of rice varieties in relation to the Si parameters and $\hat{\mu}+\hat{g}_{i}$ were also observed by Colombari Filho et al. (2013), in which $84 \%$ of the varieties were common to the two parameters, while in sugarcane, Oliveira et al. (2005) reported $80 \%$ of concordance of the best sugarcane clones selected for yield. These results reinforce the need to use, whenever possible, different criteria for selecting superior genotypes.

Of the materials grown (witnesses), the variety BRS Dourada was more stable in all evaluated experiments, while the variety Eucalipto, which is considered as tolerant to PPD, was highly unstable, ranking in 19th position (Table 4). The Si parameter considers both the stability and the PPD tolerance, and there is a penalty for unstable accessions. Therefore, the $\mathrm{Si}$ values are the AUP-PPD values, and are penalized by their instability, which facilitates the selection of the most resistant and stable accessions in different environments. According to Resende (2007), the main advantage in calculating the stability of accessions based on genotype refers to the most accurate estimation of genetic effects, when the genotypes are considered as a random factor.

Regarding adaptability, there was $73 \%$ agreement between the most stable accessions and those with high adaptability (BGM0452, BGM0601, BGM0623, BGM0624, BGM0626, BGM0640, BGM0745, BGM0878, BGM1024, BGM1037, BGM1067, BGM1124, BGM1190, BGM1209, BGM1291, BGM1342, BGM1370, BGM1371, BGM1417, BGM1508, BGM1567, and BGM1607) (Table 4). In this case, the Ai parameter capitalizes the responsiveness of each accession to the improvement of the environment (in this study understood as experiments with lower average of PPD severity). In the mixed model methodology used to calculate Ai, 
the predicted genotypic values are expressed as a proportion of the overall mean of each environment $\left(\mu_{j}\right)$ and then parameters on the scale of the measured attribute are obtained by multiplying Ai by the overall mean of the experiments $(\bar{X})$. The ranking of varieties currently used by farmers for the Ai parameter was observed to be very similar to that of the Si.

Table 4. Stability estimates ( $\mathrm{Si}$ ) and adaptability (Ai) predicted by BLUP analysis for the 30 cassava accessions most tolerant to PPD.

\begin{tabular}{|c|c|c|c|c|c|c|}
\hline \multicolumn{3}{|c|}{ Stability } & \multicolumn{4}{|c|}{ Adaptability } \\
\hline Rank & Accession & $\mathrm{Si}$ & Rank & Accession & $\mathrm{Ai}$ & $\mathrm{Ai}^{*} * \overline{\mathrm{X}}$ \\
\hline 418 & BGM1342 & 60.01 & 418 & BGM1342 & 0.04 & 66.95 \\
\hline 417 & BGM0878 & 117.98 & 417 & BGM0878 & 0.08 & 131.63 \\
\hline 416 & BGM0623 & 137.47 & 416 & BGM0623 & 0.10 & 153.38 \\
\hline 415 & BGM1124 & 159.88 & 415 & BGM1209 & 0.13 & 201.96 \\
\hline 414 & BGM1067 & 188.02 & 414 & BGM1124 & 0.13 & 209.58 \\
\hline 413 & BGM1567 & 211.04 & 413 & BGM1567 & 0.15 & 235.46 \\
\hline 412 & BGM0624 & 214.07 & 412 & BGM1024 & 0.15 & 239.16 \\
\hline 411 & BGM1024 & 214.35 & 411 & BGM0624 & 0.15 & 239.31 \\
\hline 410 & BGM1370 & 217.13 & 410 & BGM1067 & 0.15 & 246.47 \\
\hline 409 & BGM1190 & 220.94 & 409 & BGM1370 & 0.16 & 263.21 \\
\hline 408 & BGM0626 & 226.87 & 408 & BGM1508 & 0.18 & 291.85 \\
\hline 407 & BGM1209 & 230.16 & 407 & BGM0626 & 0.21 & 340.36 \\
\hline 406 & BGM1508 & 261.58 & 406 & BGM0745 & 0.28 & 445.68 \\
\hline 405 & BGM1524 & 276.83 & 405 & BGM1190 & 0.28 & 452.72 \\
\hline 404 & BGM0540 & 320.85 & 404 & BGM1607 & 0.29 & 460.19 \\
\hline 403 & BGM2019 & 370.91 & 403 & BGM1417 & 0.31 & 495.26 \\
\hline 402 & BGM1371 & 394.49 & 402 & BGM1371 & 0.31 & 498.02 \\
\hline 401 & BGM0745 & 399.46 & 401 & BGM0497 & 0.31 & 504.88 \\
\hline 400 & BGM1347 & 403.39 & 400 & BGM0640 & 0.34 & 553.30 \\
\hline 399 & BGM0788 & 410.26 & 399 & BGM1185 & 0.35 & 569.08 \\
\hline 398 & BGM1607 & 412.46 & 398 & BGM1203 & 0.36 & 578.83 \\
\hline 397 & BGM1311 & 425.49 & 397 & BGM0930 & 0.37 & 600.52 \\
\hline 396 & BGM0640 & 443.60 & 396 & BGM0452 & 0.38 & 615.22 \\
\hline 395 & BGM1417 & 443.90 & 395 & BGM1291 & 0.39 & 622.78 \\
\hline 394 & BGM0452 & 448.30 & 394 & BGM0276 & 0.39 & 632.02 \\
\hline 393 & BGM1037 & 477.52 & 393 & BGM1681 & 0.40 & 647.90 \\
\hline 392 & BGM1236 & 485.39 & 392 & BGM0601 & 0.41 & 652.47 \\
\hline 391 & BGM0601 & 488.85 & 391 & BGM1270 & 0.41 & 654.81 \\
\hline 390 & BGM1053 & 496.08 & 390 & BGM1672 & 0.41 & 655.12 \\
\hline 389 & BGM1291 & 501.16 & 389 & BGM1037 & 0.41 & 663.21 \\
\hline 18 & $9624-09$ & 2592.70 & 35 & $9624-09$ & 1.52 & 2434.40 \\
\hline 85 & $98150-02$ & 2128.20 & 161 & $98150-02$ & 1.13 & 1820.80 \\
\hline 269 & BRS Aipim Brasil & 1223.10 & 221 & BRS Aipim Brasil & 1.00 & 1603.30 \\
\hline 256 & BRS Caipira & 1280.60 & 250 & BRS Caipira & 0.92 & 1476.00 \\
\hline 323 & BRS Dourada & 910.16 & 318 & BRS Dourada & 0.70 & 1128.30 \\
\hline 27 & BRS Gema de Ovo & 2550.90 & 9 & BRS Gema de Ovo & 1.77 & 2846.10 \\
\hline 44 & BRS Tapioqueira & 2426.30 & 60 & BRS Tapioqueira & 1.42 & 2287.60 \\
\hline 235 & BRS Verdinha & 1367.90 & 272 & BRS Verdinha & 0.85 & 1373.10 \\
\hline 19 & Eucalipto & 2590.90 & 6 & Eucalipto & 1.80 & 2890.70 \\
\hline
\end{tabular}

Accessions underlined and italicized refer to the local or improved varieties, used as witnesses.

The harmonic mean of the relative performance of genotypic values groups into a single parameter $(\mathrm{Zi})$, which is the joint analysis of the stability and adaptability for PPD tolerance. In this case, for the selection of accessions with high PPD tolerance and high stability and adaptability for the trait, it is necessary to select those for which the estimated $\mathrm{Zi}$ was less than 1 (contrary to what is desired when the goal is to increase the value of the trait). Therefore, on average, the 30 accessions with low $\mathrm{Zi}$ (Table 5) corresponded to 0.23 times the 
average PPD severity, using the average of all experiments in which it was evaluated. Of the nine witnesses evaluated, six presented a $\mathrm{Zi}$ value above 1.00 and therefore, presented PPD severity above the average of all accessions.

Table 5. Simultaneous estimates of stability and adaptability of genotypic values ( $\mathrm{Zi}$ ) predicted by BLUP analysis for the 30 cassava accessions most tolerant to PPD.

\begin{tabular}{l|l|c|c|c|l|c|c}
\hline Rank & Accession & $\mathrm{Zi}$ & $\mathrm{Zi} * \overline{\mathrm{X}}$ & Rank & Accession & $\mathrm{Zi}$ & $\mathrm{Zi} * \overline{\mathrm{X}}$ \\
\hline 418 & BGM1342 & 0.04 & 66.95 & 398 & BGM1311 & 0.30 & 485.33 \\
\hline 417 & BGM0878 & 0.08 & 131.63 & 397 & BGM1417 & 0.31 & 495.26 \\
\hline 416 & BGM0623 & 0.10 & 153.38 & 396 & BGM0928 & 0.31 & 500.96 \\
\hline 415 & BGM0624 & 0.11 & 182.78 & 395 & BGM0497 & 0.31 & 504.88 \\
\hline 414 & BGM1190 & 0.12 & 188.57 & 394 & BGM1347 & 0.32 & 510.47 \\
\hline 413 & BGM1209 & 0.12 & 196.69 & 393 & BGM0452 & 0.33 & 527.39 \\
\hline 412 & BGM1124 & 0.13 & 209.58 & 392 & BGM0640 & 0.33 & 529.18 \\
\hline 411 & BGM1567 & 0.15 & 235.46 & 391 & BGM1185 & 0.35 & 569.08 \\
\hline 410 & BGM1024 & 0.15 & 239.16 & 390 & BGM1236 & 0.35 & 569.26 \\
\hline 409 & BGM1067 & 0.15 & 246.47 & 389 & BGM1053 & 0.36 & 577.08 \\
\hline 408 & BGM1370 & 0.16 & 263.16 & 34 & 9624-09 & 1.51 & 2429.78 \\
\hline 407 & BGM0626 & 0.18 & 284.24 & 154 & 98150-02 & 1.13 & 1820.81 \\
\hline 406 & BGM1508 & 0.18 & 291.85 & 208 & BRS Aipim Brasil & 1.01 & 1603.30 \\
\hline 405 & BGM1524 & 0.20 & 314.14 & 241 & BRS Caipira & 0.89 & 1435.45 \\
\hline 403 & BGM0540 & 0.23 & 366.14 & 315 & BRS Dourada & 0.65 & 1039.02 \\
\hline 402 & BGM2019 & 0.26 & 424.48 & 9 & BRS Gema de Ovo & 1.77 & 2846.13 \\
\hline 401 & BGM0745 & 0.28 & 445.68 & 57 & BRS Tapioqueira & 1.42 & 2285.54 \\
\hline 400 & BGM1607 & 0.29 & 460.19 & 257 & BRS Verdinha & 0.85 & 1362.45 \\
\hline 399 & BGM0788 & 0.29 & 468.37 & 6 & Eucalipto & 2890.67 \\
\hline
\end{tabular}

Accessions underlined and italicized refer to the local or improved varieties, used as witnesses.

Of those accessions with high stability and adaptability for PPD tolerance, 26 were common to the Si parameter, 21 to the Ai parameter, and 19 to all three parameters. Unlike that observed in the present study, Farias Neto et al. (2013) reported complete agreement of the three most productive cassava genotypes based on $\mathrm{Si}, \mathrm{Ai}$, and $\mathrm{Zi}$ parameters. Gonçalves et al. (2014) also demonstrated that all five sugarcane clones selected according to their Zi parameter also ranked as having the highest sugar yield. Therefore, those authors demonstrated an order of clone maintenance based on the $\mathrm{Si}, \mathrm{Ai}$, and $\mathrm{Zi}$ parameters, indicating that these methods have a certain degree of agreement between the positions of genotypes. In contrast, if we only consider the selection of three more tolerant cassava accessions to PPD (Tables 4 and 5), their ranking remains unchanged. Therefore, factors that contribute most to inconsistency in the selection and ordering of genotypes based on $\mathrm{Si}, \mathrm{Ai}$, and $\mathrm{Zi}$ parameters are the number of accessions used in the screening, the genetic variability present, and different environmental responses. Even when there are small discrepancies in the ranking of cassava to different parameters, this result indicates that reliable prediction of genetic values can be made based only on the Zi parameter, which includes the attributes of genotypic stability and adaptability. The witness with best ranking was the BRS Dourada (315th). Based on this parameter, the local variety Eucalipto, which is considered tolerant to PPD under field conditions, was ranked only in the 6th position (Table 5).

To continue research related to the introduction of PPD tolerance in M. esculenta, the 19 following accessions: BGM0452, BGM0623, BGM0624, BGM0626, BGM0640, BGM0745, BGM0878, BGM1024, BGM1067, BGM1124, BGM1190, BGM1209, BGM1342, BGM1370, BGM1371, BGM1417, BGM1508, BGM1567, and BGM1607, that were common 
to all criteria for identifying genotypes tolerant, stable and adapted to low occurrence of PPD were selected and used to calculate the potential genetic gains. The genetic gains based on the selection of these cassava accessions were $-55.94,-466.86,-397.72$, and $-444.03 \%$, and for the $\hat{\mu}+\hat{g}_{i}, \mathrm{Si}, \mathrm{Ai}$, and Zi parameters, respectively (Table 6), when compared with the average for each parameter. Moreover, genetic gains were high even when the average of the 19 accessions was compared with the average of the witnesses for each parameter, i.e., -69.16, $-620.52,-514.12$, and $-565.73 \%$ for $\hat{\mu}+\hat{g}_{i}, \mathrm{Si}, \mathrm{Ai}$, and $\mathrm{Zi}$, respectively. In addition, regardless of the parameter, the average of the witnesses was always higher than those of the selected accessions, indicating that PPD severity was high.

Table 6. Average, range, and gains by selection of the 19 cassava accessions common to selection based on the predicted genotypic values $\left(\hat{\mu}+\hat{g}_{i}\right)$, genotypic stability (Si), genotypic adaptability (Ai), and stability + genotypic adaptability $(\mathrm{Zi})$.

\begin{tabular}{|c|c|c|c|c|c|c|c|c|}
\hline \multirow[t]{3}{*}{ Accessions } & \multicolumn{4}{|c|}{$\hat{\mu}+\hat{g}_{i}$} & \multicolumn{4}{|c|}{$\mathrm{Si}$} \\
\hline & \multirow[t]{2}{*}{ Mean } & \multirow[t]{2}{*}{ Range } & \multicolumn{2}{|c|}{ Gain (\%) } & \multirow[t]{2}{*}{ Mean } & \multirow[t]{2}{*}{ Range } & \multicolumn{2}{|c|}{ Gain (\%) } \\
\hline & & & $\bar{X} g$ & Test & & & $\bar{X} g$ & Test \\
\hline Selected & 1030.05 & 633.04 to1187.44 & -55.94 & -69.16 & 263.25 & 60.01 to 448.30 & -466.86 & -620.52 \\
\hline Witnesses & 1742.39 & 1322.99 to 2211.00 & 7.81 & & 1896.75 & 910.16 to 2592.70 & 21.33 & \\
\hline \multirow[t]{3}{*}{ Accessions } & \multicolumn{4}{|c|}{$\mathrm{Ai}$} & \multicolumn{4}{|c|}{$\mathrm{Zi}$} \\
\hline & \multirow[t]{2}{*}{ Mean } & \multirow[t]{2}{*}{ Range } & \multicolumn{2}{|c|}{ Gain (\%) } & \multirow[t]{2}{*}{ Mean } & \multirow[t]{2}{*}{ Range } & \multicolumn{2}{|c|}{ Gain (\%) } \\
\hline & & & $\bar{X} g$ & Test & & & $\bar{X} g$ & Test \\
\hline Selected & 323.14 & 66.95 to 615.22 & -397.72 & -514.12 & 295.63 & 66.95 to 529.18 & -444.03 & -565.73 \\
\hline Witnesses & 1984.48 & 1128.30 to 2890.70 & 18.95 & & 1968.13 & 1039.02 to 2890.67 & 18.28 & \\
\hline
\end{tabular}

These results demonstrate that it may be possible to introduce PPD tolerance in commercial cassava varieties, considering the use of genetic parameters that permit the breeder to reliably infer the genotypic value of the individual, even in the presence of a $\mathrm{G} x \mathrm{E}$ interaction. Currently, the vast majority of procedures that analyze the $\mathrm{G} \times \mathrm{E}$ interaction use phenotypic means, thereby estimating the phenotypic adaptability and stability. In turn, the $\mathrm{Zi}$ method is based on genotypic values predicted via mixed models, which can employ the terms genotypic adaptability and stability. Advantages of the $\mathrm{Zi}$ parameter include its application in experiments with unbalanced data, considering genotypic effects as random, and providing breeding values' already discounted by its instability, which facilitates the selection of the most tolerant and stable accessions in different environments. (Resende, 2007).

\section{Perspectives for introducing PPD tolerance in cassava}

While it is recognized that PPD is a major problem affecting cassava production on a global level, research into mitigating its effects is relatively recent. Initially, barriers to the advancement of research in this area involved the lack of genetic variability available in cassava germplasm for PPD tolerance (Ceballos et al., 2004) and the presence of a positive correlation between dry matter content in the roots and PPD tolerance (Sánchez et al., 2006). However, Morante et al. (2010) demonstrated that there was sufficient genetic variability in M. esculenta germplasm to incorporate this trait in new cassava varieties through conventional breeding.

A basic point to consider when developing an efficient breeding program to generate varieties with PPD tolerance is knowledge of the heritage of the trait. Genetic parameters related to PPD severity in cassava obtained in this study provide practical information to guide 
breeders when choosing suitable breeding methods to achieve maximum genetic gains in the segregating populations. Despite the high magnitude of the interaction $\left(\hat{\sigma}_{i}^{2}=52 \%\right)$, there is a strong genetic component $\left(\sigma_{g}^{2}=37 \%\right)$ associated with PPD tolerance, which allows selection of the best accessions for crosses or even for use per se in cassava production system, if they have other desirable agronomic traits.

As the G x E interaction was significant for PPD, it was not possible to indicate the best cassava accessions based on their average response in different experiments, because the materials presented different response patterns. In this case, the $\mathrm{G} x \mathrm{E}$ interaction can be better understood when considering the adaptability and stability of genotypes, because it is possible to check the level of genotype response to an environmental stimulus and yield maintenance against environmental variation (Maia et al., 2009). Specifically in the case of PPD tolerance, the $\mathrm{Zi}$ method permitted the selection of 19 common cassava accessions to the $\hat{\mu}+\hat{g}_{i}, \mathrm{Si}$, and $\mathrm{Ai}$ parameters, which presented lower PPD severity and retained a good rank in all experiments, thus having less $\mathrm{G} \times \mathrm{E}$ interaction and consequently less environmental influence on the trait.

The 19 selected cassava accessions with good tolerance to PPD may be used in crosses with elite varieties to generate segregating populations via recurrent selection. However, the multigenic nature of agronomic traits of interest, such as root and starch yield, will require additional effort to select the best individuals for these segregating populations, considering that the strong non-additive effect on the expression of productive traits may break favorable gene combinations. Despite these difficulties inherent in the selection of quantitative traits, the genetic control of PPD tolerance as well as its stability demonstrates the possibility of success when using varieties as an effective method of controlling this abiotic stress in cassava.

\section{Conflicts of interest}

The authors declare no conflict of interest.

\section{ACKNOWLEDGMENTS}

The authors thank FAPESB, CAPES, and CNPq for the financial assistance and scholarship support.

\section{REFERENCES}

Aina OO, Dixon AGO and Akinrinde EA (2007). Genetic variability in cassava as it influences storage root yield in Nigeria. J. Biol. Sci. 7: 765-770. http://dx.doi.org/10.3923/jbs.2007.765.770

Allem AC (2002). Cassava: biology, production and utilization (Hillocks RJ, Thresh JM and Bellotii AC, eds.). The origins and taxonomy of cassava Natural Resources Institute, University of Greenwich, 1-16.

Bastos IT, Barbosa MHP, Resende MDV, Perternelli LA, et al. (2007). Avaliação da interação genótipo x ambiente em cana-de-açúcar via modelos mistos. Pesq. Agropec. Trop. 37: 195-203.

Buschmann H, Rodriguez MX, Tohme J and Beeching JR (2000). Accumulation of hydroxycoumarins during post-harvest deterioration of tuberous roots of cassava (Manihot esculenta Crantz). Ann. Bot. (Lond.) 86: 1153-1160. http://dx.doi. org/10.1006/anbo.2000.1285

Ceballos H, Iglesias CA, Pérez JC and Dixon AG (2004). Cassava breeding: opportunities and challenges. Plant Mol. Biol. 56: 503-516. http://dx.doi.org/10.1007/s11103-004-5010-5

Cereda MP and Vilpoux O (2003). Conservação de raízes. Tecnologia, usos e potencialidades de tuberosas amiláceas latino americanas (Cereda MP and Vilpoux O, eds.), São Paulo, Fundação Cargil, 13-29.

Colombari Filho JM, Resende MDV, Morais OP, Castro AP, et al. (2013). Upland rice breeding in Brazil: a simultaneous genotypic evaluation of stability, adaptability and grain yield. Euphytica 192: 117-129. http://dx.doi.org/10.1007/ $\underline{\text { s10681-013-0922-2 }}$ 
FAO (Food Agriculture Organization) (2014). Available at [http://faostatfaoorg/site/339/defaultaspx]. Accessed June 15, 2015.

Farias Neto JT, Moura EF, Resende MDV, Celestino Filho P, et al. (2013). Genetic parameters and simultaneous selection for root yield, adaptability and stability of cassava genotypes. Pesquisa Agropecu. Bras. 48: 1562-1568. http://dx.doi. org $/ 10.1590 / \mathrm{S} 0100-204 X 2013001200005$

Fukuda WMG (2005). Associação brasileira dos produtores de amido de mandioca Embrapa pesquisa mandioca para indústria de amido, Embrapa.

Gomes FP (2000). Curso de Estatística Experimental, Piracicaba, ESALQ.

Gonçalves GM, Viana AP, Amaral AT, Junior. and Resende MDV (2014). Breeding new sugarcane clones by mixed models under genotype by environmental Interaction. Sci. Agric. 71: 66-71. http://dx.doi.org/10.1590/S010390162014000100009

Han Y, Gomez-Vasquez R, Reilly K, Li H, et al. (2001). Hydroxyproline-rich glycoproteins expressed during stress responses in cassava. Euphytica 120: 59-70. http://dx.doi.org/10.1023/A:1017547419332

Huang J, Bachem C, Jacobsen E and Visser RGF (2001). Molecular analysis of differentially expressed genes during postharvest deterioration in cassava (Manihot esculenta Crantz) tuberous roots. Euphytica 120: 85-93. http://dx.doi. org/10.1023/A:1017555605219

Iyer S, Mattinson DS and Fellman JK (2010). Study of the early events leading to cassava root postharvest deterioration. Trop. Plant Biol. 3: 151-165. http://dx.doi.org/10.1007/s12042-010-9052-3

Koblitz MGB (2011). Mandioca. Matérias-primas alimentícias: composição e controle de qualidade, 36-41.

Luengo RFA and Galbo AG (2009). Embalagens para comercialização hortaliças e frutas no Brasil Brasília, DF: Embrapa Hortaliças.

Maia MCC, Resende MDV, Paiva JR, Cavalcanti JJV, et al. (2009). Seleção simultânea para produção, adaptabilidade e estabilidade genotípicas em clones de cajueiro, via modelos mistos. Pesq. Agropec. Trop. 39: 43-50.

Morante N, Sanchez T, Ceballos H, Calle F, et al. (2010). Tolerance to postharvest physiological deterioration on in cassava roots. Crop Sci. 50: 1333-1338. http://dx.doi.org/10.2135/cropsci2009.11.0666

Oliveira EJ, Santana FA, Oliveira LA and Santos VS (2014). Genetic parameters and prediction of genotypic values for root quality traits in cassava using REML/BLUP. Genet. Mol. Res. 13: 6683-6700. http://dx.doi.org/10.4238/2014. August.28.13

Oliveira EJ, Aidar ST, Morgante CV, Chaves ARM, et al. (2015). Genetic parameters for drought-tolerance in cassava. Pesquisa Agropecu. Bras. 50: 233-241. http://dx.doi.org/10.1590/S0100-204X2015000300007

Oliveira RA, Resende MDV, Daros E, Bespalhok-Filho JC, et al. (2005). Genotypic evaluation and selection of sugarcane clones in three environments in the State of Paraná. Crop Breed. Appl. Biotechnol. 5: 426-434. http://dx.doi. org/10.12702/1984-7033.v05n04a08

Paranaíba JLV, Chagas SJR and Costa L (1996). Efeitos da poda e uso de embalagens na conservação de raízes de mandioca durante o armazenamento. Pesquisa Agropecu. Bras. 31: 269-276.

Reilly K, Han Y, Tohme J and Beeching JR (2001). Isolation and characterisation of a cassava catalase expressed during post-harvest physiological deterioration. Biochim. Biophys. Acta 1518: 317-323. http://dx.doi.org/10.1016/S0167$\underline{4781(01) 00195-6}$

Reilly K, Gomez-Vasquez R, Buschman H, Tohme J, et al. (2003). Oxidative stress responses during cassava post-harvest physiological deterioration. Plant Mol. Biol. 53: 669-685. http://dx.doi.org/10.1023/B:PLAN.0000019076.76614.88

Reilly K, Gómez-Vásquez R, Buschmann H, Tohme J, et al. (2004). Oxidative stress responses during cassava post-harvest physiological deterioration. Plant Mol. Biol. 56: 625-641.http://dx.doi.org/10.1007/s11103-005-2271-6

Reilly K, Bernal D, Cortés DF, Gómez-Vásquez R, et al. (2007). Towards identifying the full set of genes expressed during cassava post-harvest physiological deterioration. Plant Mol. Biol. 64: 187-203. http://dx.doi.org/10.1007/ s11103-007-9144-0

Resende MDV (2002a). Genética Biométrica e Estatística no Melhoramento de Plantas Perenes Brasília: Embrapa Informação Tecnológica, Embrapa Florestas, Colombo.

Resende MDV (2002b). Software Selegen-Reml/Blup, Embrapa Florestas, Colombo.

Resende MDV (2007). Matemática e estatística na análise de experimentos e no melhoramento genético, Embrapa Florestas, Colombo.

Resende MDV and Duarte JB (2007). Precisão e controle de qualidade em experimentos de avaliação de cultivares. Pesq. Agropec. Trop. 37: 182-194.

Rodrigues WP, Vieira HD, Barbosa DHSG, Souza Filho GR, et al. (2013). Adaptability and genotypic stability of Coffea arabica genotypes based on REML/BLUP analysis in Rio de Janeiro State, Brazil. Genet. Mol. Res. 12: 2391-2399. http://dx.doi.org/10.4238/2013.July.15.2

Rosado AM, Rosado TB, Alves AA, Laviola BG, et al. (2012). Seleção simultânea de clones de eucalipto de acordo com a produtividade, estabilidade e adaptabilidade. Pesquisa Agropecu. Bras. 47: 964-971. http://dx.doi.org/10.1590/ $\underline{\mathrm{S} 0100-204 X 2012000700013}$ 
Salcedo A, Del Valle A, Sanchez B, Ocasio V, et al. (2010). Comparative evaluation of physiological post-harvest root deterioration of 25 cassava (Manihot esculenta) accessions: visual vs hydroxycoumarins fluorescent accumulation analysis. Afr. J. Agric. Res. 5: 3138-3144.

Sánchez T, Chávez AL, Ceballos H, Rodriguez-Amaya DB, et al. (2006). Reduction or delay of post-harvest physiological deterioration in cassava roots with higher carotenoid content. J. Sci. Food Agric. 86: 634-639. http://dx.doi. org $/ 10.1002 /$ jsfa. 2371

Souza LS, Farias AR, Mattos PLP and Fukuda WMG (2006). Aspectos Socioeconômicos e Agronômicos da Mandioca, Embrapa Mandioca e Fruticultura, Cruz das Almas.

Venturini MT, Santos VS and Oliveira EJ (2015). Procedures for evaluating the tolerance of cassava genotypes to postharvest physiological deterioration. Pesquisa Agropecu. Bras. 50: 562-570. http://dx.doi.org/10.1590/S0100204X2015000700006

Wenham JE (1995). Post-harvest deterioration of cassava. A biotechnology perspective FAO Plant Production and Protection Paper 130NRI/FAO.

Wheatley CC and Schwabe WW (1985). Scopoletin involvement in post-harvest deterioration of cassava root. J. Exp. Bot. 36: 783-791. http://dx.doi.org/10.1093/jxb/36.5.783

Yang RC (2007). Mixed-model analysis of crossover genotype environment interactions. Crop Sci. 47: 1051-1062. http:// dx.doi.org/10.2135/cropsci2006.09.0611 